Minton, J. (1939).- "The one eyed worker in industry." Trans. Ophthal. Soc. U.K., Vol. LIX, Part 1.

WESTON, H. C. and ADAMS, S. (1927).- "The effects of eyestrain on the output of linkers in the hosiery business." Industrial Fatigue Research Board Report, No. 40.

(1928). - "On the relief of eyestrain among persons performing very fine work." Industrial Fatigue Research Board Report, No. 49.

"Further experiences on the use of special spectacles in very fine processes." Industrial Health Research Board, No. 5.

NATIONAL "INSTITUTE FOR THE BLIND.- "Skilled hands of the blind." "To employers' and employment exchange managers," and other pamphlets dealing with employment of the blind.

\title{
ANNOTATIONS
}

\section{An Error in Diagnosis}

Border-line cases between two special departments in surgery are often intriguing. Some forty years ago, when the writer was house surgeon to the ophthalmic department, an elderly man was admitted for marked ectropion of the left upper lid. The lid was completely turned back upon itself and kept in this position by a tense band of tissue leading towards the inner end of the eyebrow where was a puckered scar attached to bone. The man said he had had abscesses in the forehead for years and had been treated in out-patients. His out-patient book was found, from which it appeared that twenty or more years previously he had been under treatment by one of the surgeons and the diagnosis made at the time was gumma of the skull. Much iodide of potash had run down his throat since. The ophthalmic surgeon incised the puckered scar, freed the lid which resumed its proper place, and the man was discharged soon after. Some months later, when we were house surgeon to the hospital, this man was re-admitted with ectropion as before. $\mathrm{He}$ was referred to our surgeon who was inclined to consider the primary cause as a gumma of the skull. We had no idea what made us offer an opinion unless it was that the surgeon asked what we thought; but, looking at the site of the puckered scar it occurred to us that his trouble might all the time have been in the frontal sinus and we suggested a reference to the nose and throat surgeon. This was done and old standing disease was found in the sinus. The man was treated surgically and some saving in the expenditure of iodide of potash was made. It seems odd that such a prolonged history of chronic disease should have persisted without a proper nasal examination. But the error of repeating a medicine, which may do good and cannot do much harm, is an easy one to fall into in out-patient practice. Also the house surgeon must know his chief and his foibles pretty well before he 
starts diagnosing his cases for him. Some elders do not take at all kindly to receiving suggestions from so insignificant a person as a house surgeon. Brilliant careers have in the past been much delayed by a man in the position of a house surgeon being too fond of advising his chief as to diagnosis and treatment. It should be possible with tact to suggest an obvious line of examination in such a case without treading on elderly toes. But house surgeons should beware.

\section{Overwork}

It was recently announced in the lay press that a certain eminent gentleman from overseas had "disclosed . . . that he had become totally. blind. While his general health was perfect, he said, 70 years of overwork had brought a paralysis of his optic nerve." His age was given as 83 .

While refraining from commenting on the meaning, if any, of the phrase " 70 years of overwork," it is pertinent to comment on the question of damaging any organ of the body by use. So often one hears of visual defects brought on by excessive use of the eyes, by working under artificial light, by reading in bed-the list is limitless. The writer has yet to be convinced that any healthy organ has ever been permanently damaged by work or overwork; nature has her own controls and it is not fanciful to conclude that function is interrupted before damage begins. In the field of cardiology, the sympathy so commonly extended to the hearts of men who have indulged in severe athletic strain has been proved to be misplaced. Reference to Bell's Life Tables has proved that the expectation of life of old rowing men is just a little above the average. One feels that it is high time that this old bogey of damage from use should be exorcised for ever. Perhaps the most important aspect of the question is the clinical; one is constantly hearing, for instance, of the patient with early cataract who has had cruel and totally unnecassary restrictions placed upon his visual activities. The writer cannot call to mind any ophthalmic condition, cther than the inflammatory or immediately post-operative, which demands that such visual capacity as remains to the patient may not be exercised to the full. The burden of defective sight is hard enough to bear in itself; further voluntary restriction is psychologically unwise and physiologically unjustified, at least until the time comes when it is proved that use may cause further damage, and it will, in the writer's opinion, be a very long time before it is proved that work, or overwork, can induce pathological changes in a healthy organ-even the optic nerve. 